ARTICLE

\title{
Direct growth of uniform carbon nitride layers with extended optical absorption towards efficient water-splitting photoanodes
}

Jiani Qin ${ }^{1}$, Jesús Barrio (10 ${ }^{1}$, Guiming Peng ${ }^{1}$, Jonathan Tzadikov ${ }^{1}$, Liel Abisdris ${ }^{1}$, Michael Volokh (1D ${ }^{1}$ \& Menny Shalom (iD) ${ }^{1 凶}$

A general synthesis of carbon nitride (CN) films with extended optical absorption, excellent charge separation under illumination, and outstanding performance as a photoanode in water-splitting photoelectrochemical cells is reported. To this end, we introduced a universal method to rapidly grow $\mathrm{CN}$ monomers directly from a hot saturated solution on various substrates. Upon calcination, a highly uniform carbon nitride layer with tuned structural and photophysical properties and in intimate contact with the substrate is obtained. Detailed photoelectrochemical and structural studies reveal good photoresponse up to $600 \mathrm{~nm}$, excellent hole extraction efficiency (up to $62 \%$ ) and strong adhesion of the $\mathrm{CN}$ layer to the substrate. The best $\mathrm{CN}$ photoanode demonstrates a benchmark-setting photocurrent density of $353 \mu \mathrm{A} \mathrm{cm}^{-2}$ (51\% faradaic efficiency for oxygen), and external quantum yield value above $12 \%$ at $450 \mathrm{~nm}$ at $1.23 \mathrm{~V}$ versus $\mathrm{RHE}$ in an alkaline solution, as well as low onset potential and good stability.

\footnotetext{
${ }^{1}$ Department of Chemistry and Ilse Katz Institute for Nanoscale Science and Technology, Ben-Gurion University of the Negev, Beer-Sheva 8410501 , Israel.

凶email: mennysh@bgu.ac.il
} 
C arbon nitride $(\mathrm{CN})$ materials have emerged as promising cheap and benign semiconductors for photoelectrochemical (PEC) cells during the last decade, owing to their stability under harsh conditions and suitable energy band edges for water-splitting and other chemical transformations ${ }^{1-9}$. However, the PEC performance of CN materials is still low compared to the state-of-art semiconductors ${ }^{10-14}$ and to their possible theoretical value. The $\mathrm{CNs}^{\prime}$ intrinsic moderate light-harvesting properties and poor charge separation properties alongside a limited variety of growth methods and monomers, which can be utilized to grow a continuous $\mathrm{CN}$ layer with an intimate contact to the substrate ${ }^{4,15-18}$ are obstacles to their successful PEC implementation. To date, several methods have been used to synthesize $\mathrm{CN}$ films, such as the doctor-blade technique, which require supramolecular assemblies as the precursor ${ }^{19,20}$, thermal vapor condensation ${ }^{21-23}$, solvothermal methods $s^{24,25}$, microcontact printing ${ }^{26}$ and liquid-based methods ${ }^{27-29}$. However, despite the great progress achieved with the above-mentioned growth and deposition methods, most of them only permit the use of a restricted range of monomers as the starting precursor and some require more complicated conditions that are not suitable for all substrates and have scalability difficulties ${ }^{30-32}$. The small number of growth methods and usable monomers hinders the quest for $\mathrm{CN}$ materials with enhanced optical and electronic properties, which are mandatory characteristics for further $\mathrm{CN}$ PEC improvement. Therefore, new deposition methods that allow the use of a wider range of monomers to cast multiple $\mathrm{CN}$ layers with diverse chemical, morphological, and photophysical properties are still highly needed to achieve the required substantial progress towards practical CN-based PECs. Moreover, to this day, most of the $\mathrm{CN}$ materials have only exhibited strong light response up to $\sim 420 \mathrm{~nm}$ in PEC, because of their wide bandgap, which is only suitable for harvesting a small portion of the solar spectrum $^{33-36}$. Therefore, increasing the photoresponse of $\mathrm{CN}$ layers in the visible region is crucial for further PEC activity enhancement.

Herein we demonstrate a simple and general method to grow porous $\mathrm{CN}$ films with extended optical absorption, improved charge separation properties under illumination, and intimate contact with the substrate via the direct and fast growth of monomers from saturated solutions, followed by calcination at high temperature. In addition, to improve the charge separation, connection to the substrate, and overall PEC properties, we introduce melamine vapor during the layer's growth ${ }^{37}$. The best $\mathrm{CN}$ film, based on thiourea as a precursor, $\mathrm{CN}_{\mathrm{TM}}$, exhibits a photoanodic photocurrent of $353 \mu \mathrm{A} \mathrm{cm}^{-2}$ at $1.23 \mathrm{~V}$ versus (vs.) reversible hydrogen electrode (RHE) in $0.1 \mathrm{M} \mathrm{KOH}$ aqueous solution under one-sun illumination, a low onset potential of $0.32 \mathrm{~V}$, and a high incident photon-to-current conversion efficiency (IPCE) up to $600 \mathrm{~nm}$. Notably, gas evolution rates of $1.88 \mu \mathrm{mol} \mathrm{h}^{-1} \mathrm{~cm}^{-2}$ for $\mathrm{H}_{2}$ and $0.91 \mu \mathrm{mol} \mathrm{h}^{-1} \mathrm{~cm}^{-2}$ for $\mathrm{O}_{2}$ are detected.

\section{Results}

Preparation and characterization of $\mathbf{C N}_{\mathrm{T}}$ films. The new synthetic path is illustrated in Fig. 1a. To deposit thiourea directly on fluorine-doped tin oxide (FTO)-coated glass, a clean FTO glass is immersed into a hot $\left(70{ }^{\circ} \mathrm{C}\right)$ saturated thiourea aqueous solution (ca. $0.9 \mathrm{~g} \mathrm{~mL}^{-1}$ ) for $1 \mathrm{~s}$ and subsequently taken out, yielding a uniform film layer of thiourea on FTO after the remaining liquid is left to dry. The thickness of the thiourea film can be tuned by sequential dip-dry cycles. Top-view scanning electron microscopy (SEM) of the thiourea film reveals a cohesive and oriented network structure (Fig. 1b), which is strikingly different from that of the pristine thiourea powder (Supplementary Fig. 1) and indicative of a good adhesion after recrystallization. Cross-sectional SEM (Fig. 1c) shows a uniform thickness and close contact to FTO. X-ray diffraction (XRD) patterns of the thiourea film and the pristine thiourea powder show similar crystal structures, with differences only in the relative intensity of some of the peaks, a result of variations in the orientation of the crystals in the samples (Fig. 1d).

The $\mathrm{CN}$ films were prepared by the calcination of the thiourea films at $500{ }^{\circ} \mathrm{C}$ for $2 \mathrm{~h}$ under nitrogen atmosphere (the proposed self-polymerization of thiourea into $\mathrm{CN}$ was given by Zhang et al. ${ }^{38}$ ); this resulted in uniform yellow-colored carbon nitride layers $\left(\mathrm{CN}_{\mathrm{T}}, \mathrm{T}\right.$ stands for thiourea) on FTO (Fig. 1a). A top-view SEM image of a $\mathrm{CN}_{\mathrm{T}}$ electrode (Fig. 2a) presents a uniform and nanostructured architecture, which is dissimilar to the corresponding $\mathrm{CN}_{\mathrm{T}}$ powder (Supplementary Fig. 2). High-magnification SEM

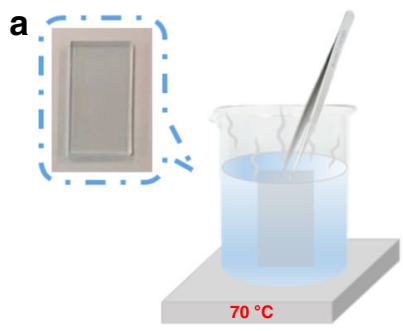

Hot saturated thiourea solution
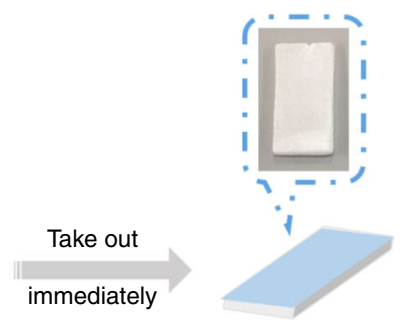

Thiourea/FTO

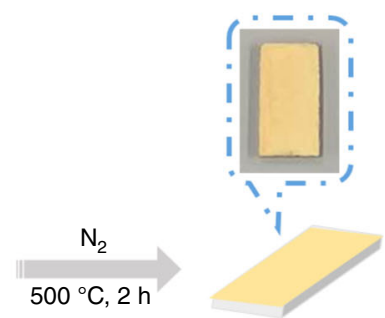

$\mathrm{CN}_{\mathrm{T}} / \mathrm{FTO}$
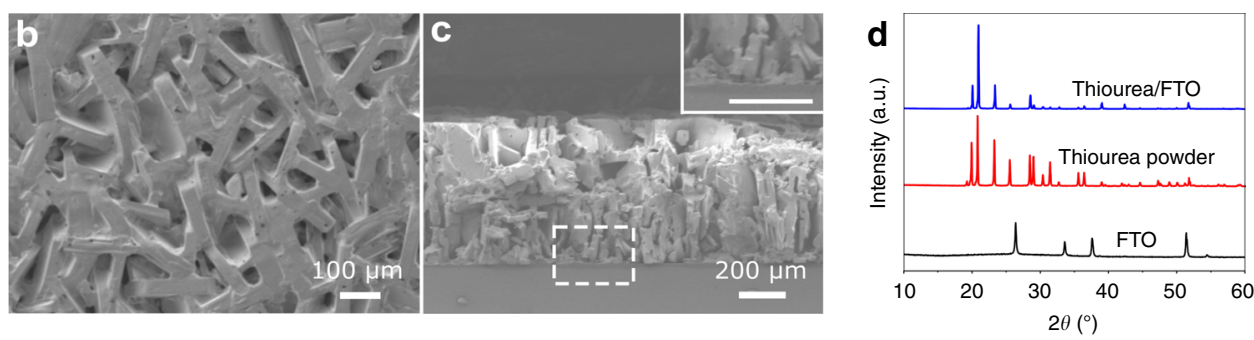

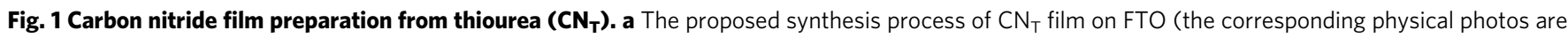
shown within the dotted line). b Top-view SEM image of the thiourea film on FTO. c Cross-sectional SEM image of a 3-layer thiourea film on FTO (inset: a magnified SEM image of the squared area). d XRD patterns of clean FTO, thiourea powder, and thiourea film on FTO. 

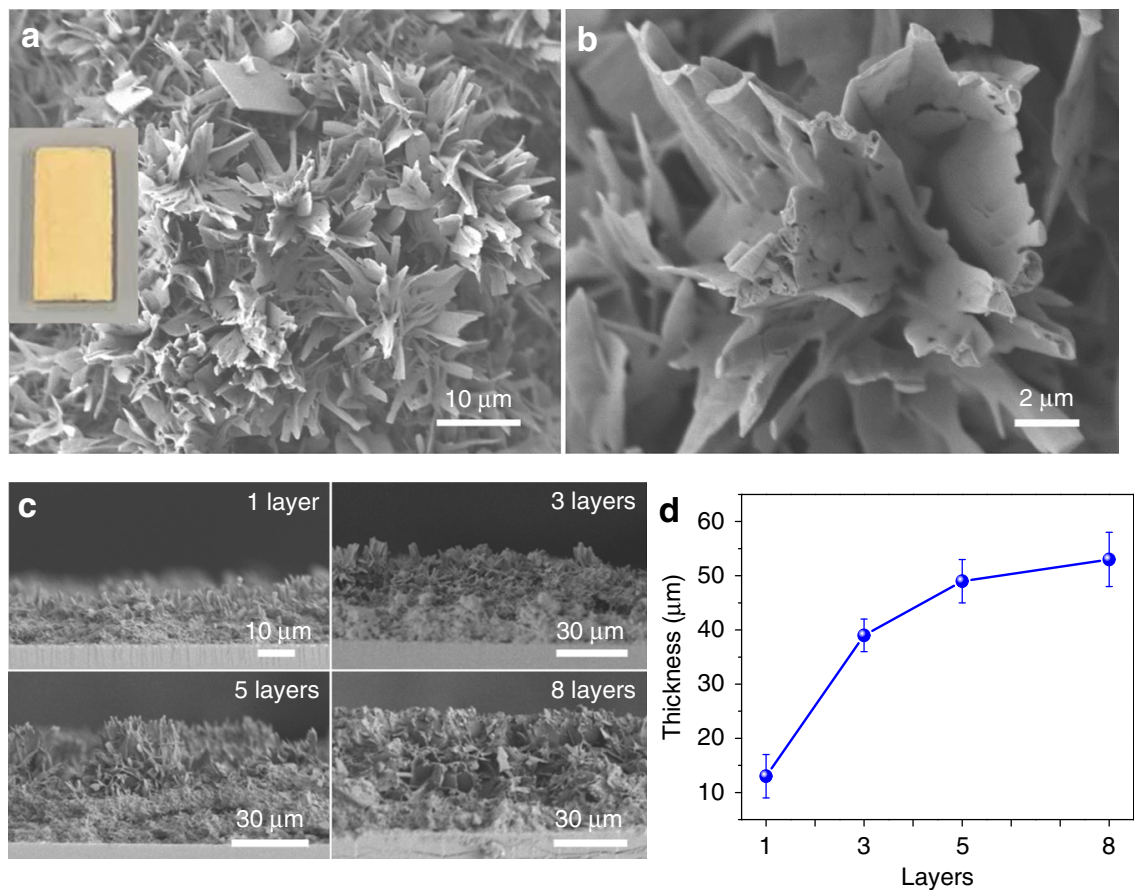

Fig. $2 \mathbf{C N}_{\mathbf{T}}$ film thickness control. a Top-view SEM image (inset: digital image of $\mathrm{CN}_{\mathrm{T}} / \mathrm{FTO}$ electrode) and $\mathbf{b}$ magnified top-view SEM image of $C \mathrm{~N}_{\mathrm{T}}$ film. c Cross-sectional SEM images of the different thicknesses $\mathrm{CN}_{\mathrm{T}}$ films on FTO. $\mathbf{d}$ Relationship between the final thickness of $\mathrm{CN}_{\mathrm{T}}$ films and the corresponding thiourea layers. Each data point represents an average of three different $\mathrm{CN}_{\mathrm{T}}$ electrodes; error bars represent standard deviation.

(Fig. 2b) discloses a nanosheets structure with many pores, owing to the release of condensation products during calcination. The thickness of $\mathrm{CN}_{\mathrm{T}}$ films (Fig. 2c) can be easily tuned from 13 to 53 $\mu \mathrm{m}$ (Fig. $2 \mathrm{~d}$ ) by adjusting the starting thickness of the thiourea layer (Supplementary Fig. 3).

All $\mathrm{CN}_{\mathrm{T}}$ electrodes present chemical structural properties that are similar to those of $\mathrm{CN}_{\mathrm{T}}$ powder (Supplementary Fig. 4), which indicates a successful $\mathrm{CN}$ layer synthesis. XRD patterns (Supplementary Fig. 4a) of all $\mathrm{CN}_{\mathrm{T}}$ electrodes exhibit a strong and sharp peak at $27.4^{\circ}$, which is attributed to the (002) interlayer distance of graphitic $\mathrm{CN}$. Another small reflection ca. $13^{\circ}$ is attributed to the in-plane heptazine repeating units, i.e., $(100)^{33}$. The Fouriertransform infrared (FTIR) spectra exhibit pronounced absorption peaks in the $1200-1600 \mathrm{~cm}^{-1}$ range (Supplementary Fig. $4 \mathrm{~b}$ ), which are assigned to the characteristic stretch modes of aromatic $\mathrm{CN}$ heterocycles. The peak at $810 \mathrm{~cm}^{-1}$ corresponds to the breathing mode of the heptazine units. The stretching vibration between 3000 and $3600 \mathrm{~cm}^{-1}$ indicates the existence of unreacted $\mathrm{NH}$ and/or $\mathrm{NH}_{2}$ groups ${ }^{33,39}$. The UV-Vis spectra of all the $\mathrm{CN}_{\mathrm{T}}$ electrodes (Supplementary Fig. 4c) disclose a direct bandgap in the $2.15-2.38 \mathrm{eV}$ range, with a long absorption tail that extends beyond $700 \mathrm{~nm}$. Altering the layer thickness from 13 to $53 \mu \mathrm{m}$ leads to a slight redshift of the optical edges, together with an increased optical density. In accordance with the absorption behavior, the photoluminescence (PL) spectra (Supplementary Fig. 4d) of all $\mathrm{CN}_{\mathrm{T}}$ electrodes indicate a decrease of the PL intensity with increasing electrode thickness probably due to the contribution of defect states (bulk recombination) and possibly also increased reabsorption of emitted photons.

The chemical composition and oxidation state of the elements in the synthesized electrode were investigated by X-ray photoelectron spectroscopy (XPS), see Supplementary Fig. 5. The high-resolution spectrum of C $1 s$ exhibits two peaks located at 284.6 and $287.9 \mathrm{eV}$, which belong to $s p^{2} \mathrm{C}-\mathrm{C}$ bonds and $\mathrm{N}-\mathrm{C}=\mathrm{N}$ coordination, respectively. In the $\mathrm{N} 1 s$ spectrum, three main peaks at 398.4, 399.9 , and $401.0 \mathrm{eV}$ were detected and assigned to $s p^{2} \mathrm{C}-\mathrm{N}=\mathrm{C}$ bonds, the tertiary nitrogen $\mathrm{N}-(\mathrm{C})_{3}$ groups, and the amino groups (C-NH-C and C- $\mathrm{NH}_{2}$ ), respectively, while a peak at $403.9 \mathrm{eV}$ was assigned to charging effects ${ }^{33,40}$. In the $\mathrm{O} 1 \mathrm{~s}$ spectrum, a peak at $532.1 \mathrm{eV}$, due to adsorbed water, was observed ${ }^{41}$. The highresolution spectrum of $S 2 p$ shows the absence of sulfur in the final $\mathrm{CN}$.

PEC performance of the $\mathrm{CN}_{\mathrm{T}}$ electrode. PEC measurements in a three-electrode configuration under one-sun illumination reveal an optimal photoresponse for a $\mathrm{CN}_{\mathrm{T}}$ layer thickness of $39 \mu \mathrm{m}$ (Fig. 3a). The photocurrent density reaches $266 \mu \mathrm{A} \mathrm{cm}^{-2}$ at $1.23 \mathrm{~V}$ vs. RHE at this thickness. These results imply that there is a sufficient electron diffusion length within the $\mathrm{CN}_{\mathrm{T}}$ electrode. However, the diffusion of electrons is not yet optimal as can be deduced from a front-side illumination measurement (Supplementary Fig. 6). Under front-side illumination, not all the photogenerated electrons reach the FTO glass due to the large distance that the electrons should travel. A further increase in the film's thickness results in a decline in photocurrent, which probably stems from reduced light penetration within the electrode and increased electron-hole recombination within the active layer before they react ${ }^{41}$. In addition to the thickness, the influence of the calcination temperature during the preparation of the $\mathrm{CN}_{\mathrm{T}}$ electrode on its morphology and PEC characteristics were also explored (Supplementary Figs. 7 and 8, respectively). As shown in Supplementary Fig. $8 \mathrm{a}$, the $\mathrm{CN}_{\mathrm{T}}$ electrode calcined at $500{ }^{\circ} \mathrm{C}$ exhibits the best PEC performance.

To determine the reproducibility of the $\mathrm{CN}_{\mathrm{T}}$ electrode PEC performance, photocurrent experiments were performed on three $\mathrm{CN}_{\mathrm{T}}$ electrodes, which were prepared in three separate synthetic batches. The photocurrent curves (Fig. 3b) of the three electrodes coincide very well (within $\pm 10 \mu \mathrm{A} \mathrm{cm}^{-2}$ ), demonstrating the high repeatability of the new synthetic path of $\mathrm{CN}_{\mathrm{T}}$ electrodes. The calculated incident photon-to-current conversion efficiency (IPCE) of $\mathrm{CN}_{\mathrm{T}}$ electrodes at several illumination wavelengths (Fig. 3c) shows a direct correlation with light absorption. A high 

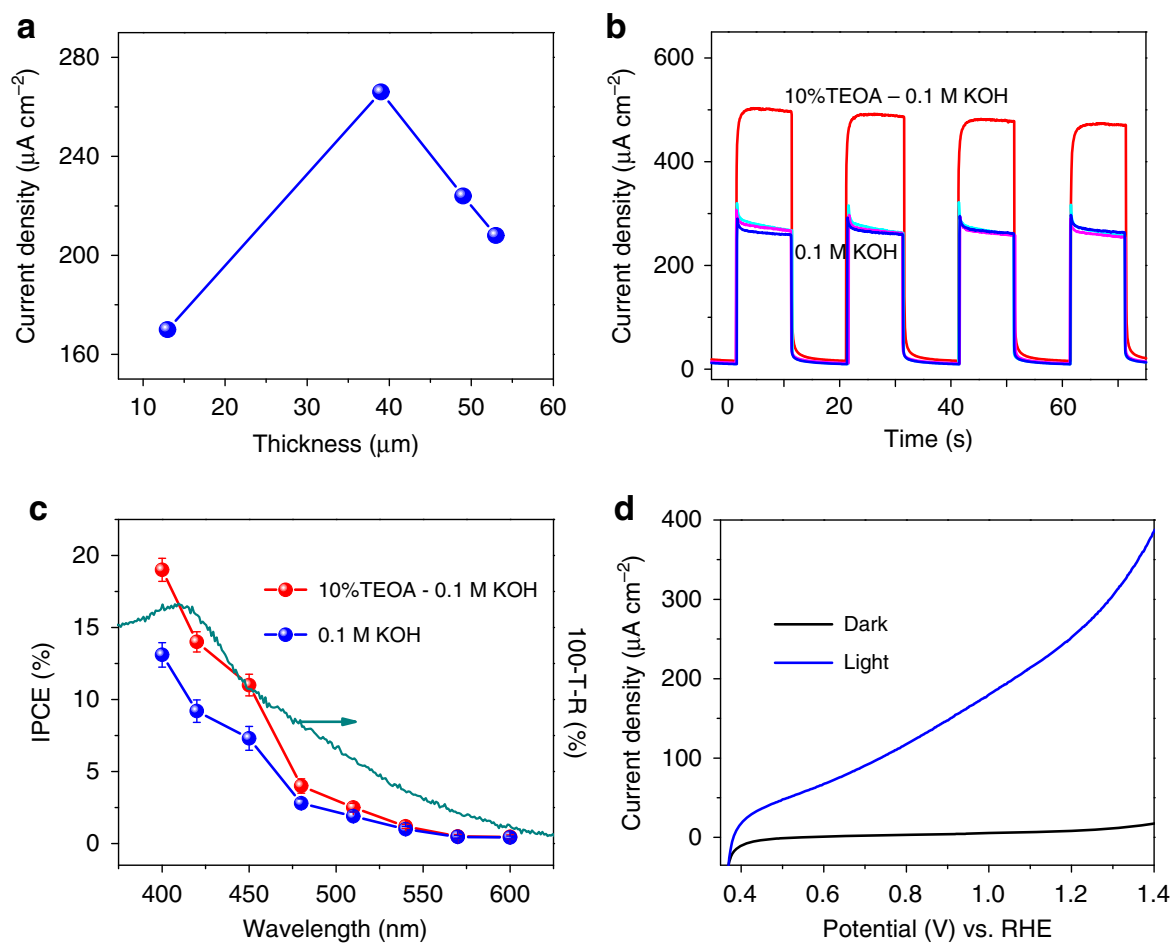

Fig. 3 PEC characterization of $\mathbf{C N}_{\mathbf{T}}$ electrodes. a Photocurrent-thickness relationship of $\mathrm{CN}_{\mathrm{T}}$ electrodes. $\mathbf{b}$ Photocurrent density curves (chronoamperometry) of $\mathrm{CN}_{\mathrm{T}}$ electrodes at $1.23 \mathrm{~V}$ vs. RHE in $0.1 \mathrm{M} \mathrm{KOH}$ (blue, cyan, and magenta lines) and in $0.1 \mathrm{M} \mathrm{KOH}$ containing $10 \%$ ( $\mathrm{V} / \mathrm{v}$ ) $\mathrm{TEOA}$ (red line). c IPCE plots of $C N_{T}$ electrode as a function of incident wavelength and UV-Vis spectrum of $C_{T}$ electrode. $\mathbf{d} L S V$ curves of $C N_{T}$ electrode in 0.1 $\mathrm{M} \mathrm{KOH}$ with and without light. All the light conditions are calibrated one-sun illumination. Each IPCE (\%) data point represents an average of three different $\mathrm{CN}_{\mathrm{T}}$ electrodes; error bars represent standard deviation.

IPCE value of $13 \%$ is achieved at $400 \mathrm{~nm}$, and a photoresponse can be detected up to $600 \mathrm{~nm}$, which was seldom reported for unmodified $\mathrm{CN}$ electrodes. Linear sweep voltammetry (LSV) curves (Fig. 3d) of $\mathrm{CN}_{\mathrm{T}}$ electrode in the dark and under one-sun illumination demonstrate a typical PEC behavior, with an onset potential at $0.38 \mathrm{~V}$ vs. RHE, and an increase in photocurrent at higher bias potentials.

To estimate the hole extraction efficiency, $10 \%(\mathrm{v} / \mathrm{v})$ triethanolamine (TEOA), an efficient hole scavenger, was added to the system. The facile hole extraction leads to an increase in the photocurrent to $470 \mu \mathrm{A} \mathrm{cm} \mathrm{cm}^{-2}$ (Fig. 3b). In good agreement with this result, the IPCE value at $400 \mathrm{~nm}$ is improved to $19 \%$ (Fig. 3c). It is assumed that most holes are successfully extracted from the layer to oxidize TEOA, essentially removing the kinetic barrier of the oxidation half-reaction, allowing a maximal photocurrent to be obtained. Based on this assumption, the calculated charge transfer efficiency of $\mathrm{CN}_{\mathrm{T}}$ electrode at $1.23 \mathrm{~V}$ vs. RHE in $0.1 \mathrm{M}$ $\mathrm{KOH}$ is $57 \%$ (Supplementary Fig. 9), which is relatively high in the absence of any co-catalyst $17,31,42$. We note, that as we could not obtain a photocurrent plateau in the presence of TEOA, the actual values are probably lower.

Growing $\mathbf{C N}_{\mathbf{T}}$ films on different substrates. To show the generality of this new method, $\mathrm{CN}_{\mathrm{T}}$ film was grown on FTO with different sizes and shapes, and on other substrates, such as carbon paper, $\mathrm{TiO}_{2}$-coated electrode, and a glass slide. Figure $4 \mathrm{a}$ and Supplementary Fig. 10 show that regardless of the size and shape of the FTO substrate, both thiourea and the resulting CN films cover the entire FTO area well. On the other substrates, uniform and continuous $\mathrm{CN}_{\mathrm{T}}$ films were also obtained (Fig. 4b-d). The corresponding SEM characterization demonstrates that the morphologies of $\mathrm{CN}_{\mathrm{T}}$ films on different substrates are similar to those on FTO (Supplementary Figs. 11-13), suggesting a negligible effect of the substrates on the resulting $\mathrm{CN}_{\mathrm{T}}$ film morphology.

Synthesis of $\mathrm{CN}$ films using different precursors. The generality of the developed $\mathrm{CN}$ film fabrication method was further demonstrated by using different monomers. Taking urea (ca. $2.4 \mathrm{~g} \mathrm{~mL}^{-1}$ at $70{ }^{\circ} \mathrm{C}$ in water) as an example, we showed that a uniform and ordered urea film on FTO can be obtained by using this method (Supplementary Fig. 14). The method was then extended to monomers with lower solubility than thiourea and urea, such as dicyandiamide (DCDA, ca. $0.3 \mathrm{~g} \mathrm{~mL}^{-1}$ at $70{ }^{\circ} \mathrm{C}$ ). Supplementary Figure 15 shows that only a partial formation of a DCDA film is obtained on FTO, due to its low solubility in water. With the addition of a preliminary seeding layer step, the formed DCDA is evenly spread on the entire FTO (Supplementary Fig. 16). After calcination, the obtained $\mathrm{CN}_{U}$ (CN synthesized from urea) electrode presents a loose coral-like morphology (Fig. 4e) while $\mathrm{CN}_{\mathrm{D}}$ (CN synthesized from DCDA) looks like blades of grass (Fig. 4h). Both show a highly uniform microstructure, dissimilar to the corresponding precursor and $\mathrm{CN}$ powders (Supplementary Figs. 14c, $16 \mathrm{e}$, and 17). Figure $4 \mathrm{f}, \mathrm{i}$ demonstrate that the resulting $\mathrm{CN}_{\mathrm{U}}$ and $\mathrm{CN}_{\mathrm{D}}$ films are well attached to the FTO and present good PEC performance (Fig. 4g, j, and Supplementary Fig. 18). High photocurrents of 368 and $133 \mu \mathrm{A} \mathrm{cm}^{-2}$ were obtained from the $\mathrm{CN}_{\mathrm{U}}$ electrode (Fig. $4 \mathrm{~g}$ ), and 277 and $145 \mu \mathrm{A} \mathrm{cm} \mathrm{cm}^{-2}$ were achieved with the $\mathrm{CN}_{\mathrm{D}}$ electrode (Fig. 4j), with or without a hole scavenger, respectively. Similarly, the two monomers can form porous and continuous $\mathrm{CN}$ films on other different substrates (Supplementary Figs. 19-21). In addition, two other monomers-ammonium thiocyanate $\left(\mathrm{NH}_{4} \mathrm{SCN}\right.$, abbreviated as NS, ca. $4.6 \mathrm{~g} \mathrm{~mL}^{-1}$ at $70{ }^{\circ} \mathrm{C}$ in water) and guanidine carbonate (abbreviated as GC, ca. $0.7 \mathrm{~g} \mathrm{~mL}^{-1}$ at $70{ }^{\circ} \mathrm{C}$ in water) -also allow uniform $\mathrm{CN}$ films formation by this 


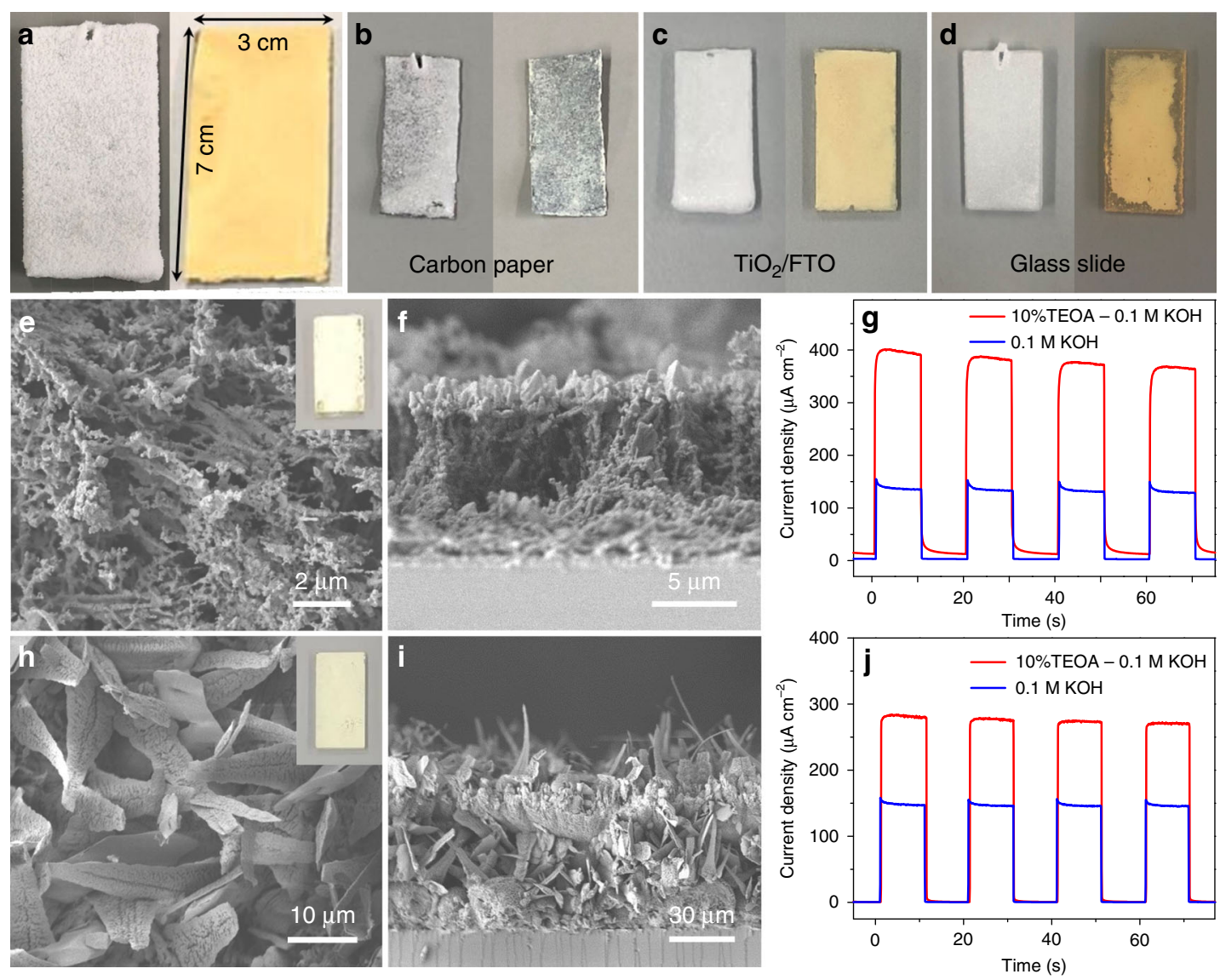

Fig. 4 Characterization of different $\mathbf{C N}$ films. Digital images of thiourea film (left) and $\mathrm{CN}_{\mathrm{T}}$ film (right) on different substrates: a Large-sized FTO, b carbon paper, c $\mathrm{TiO}_{2}$-coated electrode, and $\mathbf{d}$ glass slide. e Top-view SEM image (inset: digital image of $\mathrm{CN}_{U}$ electrode) and $\mathbf{f}$ cross-sectional SEM image of CN film on FTO. $\mathbf{g}$ Photocurrent density curves (chronoamperometry) of $\mathrm{CN}_{\cup}$ electrode at $1.23 \mathrm{~V}$ vs. RHE. h Top-view SEM image (inset: digital image of CN electrode) and $\mathbf{i}$ cross-sectional SEM image of $\mathrm{CN}_{\mathrm{D}}$ film on FTO. $\mathbf{j}$ Photocurrent density curves (chronoamperometry) of $\mathrm{CN}_{\mathrm{D}}$ electrode at $1.23 \mathrm{~V}$ vs. RHE.

method, leading to high PEC performance (Supplementary Figs. 22 and 23).

Synthesis of $\mathrm{CN}_{\mathrm{T}}$ films using other methods. For comparison, three other methods were used to synthesize CN photoelectrodes from thiourea. Direct calcination of thiourea powder spread on pristine FTO led to the formation of an uneven and cracked $\mathrm{CN}$ layer (Supplementary Fig. 24a). Drop-casting a slurry, followed by calcination at $300{ }^{\circ} \mathrm{C}$ for $1 \mathrm{~h}$ to increase adhesion gave a uniform $\mathrm{CN}$ film (Supplementary Fig. 24b). However, the layer peeled off upon contact with the electrolyte solution. A doctor-blade method, which is based on using thiourea as the precursor turned out to be infeasible owing to improper paste formation (Supplementary Fig. 24c).

Characterization and PEC performance of the $\mathbf{C N}_{\mathrm{TM}}$ electrode. As the water-splitting reaction occurs on the photoelectrode's surface, a surface modification could greatly affect the defect states and charge transfer to the electrolyte without varying the bulk properties of the photoelectrode $15,43,44$. To further improve the PEC performance of the discussed $\mathrm{CN}_{\mathrm{T}}$ electrode, melamine powder was added to the bottom of the tube, and the thiourea/ FTO was then placed close to the nozzle (Fig. 5a). After calcination, a slightly darker yellow $\mathrm{CN}$ film was obtained, named here as $\mathrm{CN}_{\mathrm{TM}}$. The surface modification greatly improves the PEC performance of the $\mathrm{CN}$; the modified $\mathrm{CN}_{\mathrm{TM}}$ electrode calcined at $550{ }^{\circ} \mathrm{C}$ shows the best performance (Fig. 5b and Supplementary Fig. 25). The photocurrent and IPCE value at $400 \mathrm{~nm}$ reach up to $353 \mu \mathrm{A} \mathrm{cm}^{-2}$ and $18 \%$, respectively (Fig. $5 \mathrm{~b}, \mathrm{c}$ ). In addition, an IPCE above $12 \%$ was measured at $450 \mathrm{~nm}$ and up to $2 \%$ at $600 \mathrm{~nm}$, indicating an improved visible light response. Chronoamperometric curves (Supplementary Fig. 26) of five different $\mathrm{CN}_{\mathrm{TM}}$ electrodes match very well (within $\pm 20 \mu \mathrm{A} \mathrm{cm}^{-2}$ ), indicating the good repeatability of the new synthetic path of $\mathrm{CN}_{\mathrm{TM}}$ electrodes. Upon addition of $10 \%(\mathrm{v} / \mathrm{v})$ TEOA hole scavenger to the system, the photocurrent increases to $565 \mu \mathrm{A} \mathrm{cm}^{-2}$ (Supplementary Fig. 27). This means an improved charge transfer efficiency of the $\mathrm{CN}_{\mathrm{TM}}$ electrode in $0.1 \mathrm{M} \mathrm{KOH}$, up to $62 \%$ (Supplementary Fig. 28) thanks to the surface modification. The improved charge separation is also evident in the lower onset potential of the $\mathrm{CN}_{\mathrm{TM}}$ electrode $\left(0.32 \mathrm{~V}\right.$ vs. RHE) than $\mathrm{CN}_{\mathrm{T}}$ electrode $(0.38 \mathrm{~V})$, indicating that a non-zero photoresponse is generated at almost $1 \mathrm{~V}$ below the potential of water oxidation (Fig. 5d). We note that these PEC values are among the bestperforming for $\mathrm{CN}$ materials in the absence of a hole scavenger (Supplementary Table 1). Based on the good performance of $\mathrm{CN}_{\mathrm{TM}}$ photoanodes, the gas evolution during the reaction was detected by gas chromatography (Supplementary Fig. 29a), which showed a nearly 2:1 molar ratio of $\mathrm{H}_{2}$ and $\mathrm{O}_{2}$ generation rate, about 1.88 and $0.91 \mu \mathrm{mol} \mathrm{h}^{-1} \mathrm{~cm}^{-2}$, respectively (Fig. 5e), with calculated faradaic efficiency (FE) of $53 \pm 1 \%$ for $\mathrm{H}_{2}$ and $51 \pm$ $1.5 \%$ for $\mathrm{O}_{2}$. After a 1 -h PEC reaction, about $50 \%$ of the initial photocurrent is preserved (Supplementary Fig. 29b). Postcharacterization of the $\mathrm{CN}_{\mathrm{TM}}$ electrode (Supplementary Fig. 30) shows that the crystallinity of the $\mathrm{CN}_{\mathrm{TM}}$ electrode becomes slightly weaker and a small peak appears at $288.7 \mathrm{eV}$ in the $\mathrm{C} 1 \mathrm{~s}$ XPS spectrum, which is assigned to the $\mathrm{C}-\mathrm{O}$ bond ${ }^{45,46}$, suggesting partial oxidation of the $\mathrm{CN}_{\mathrm{TM}}$ electrode occurred during the 1-h 

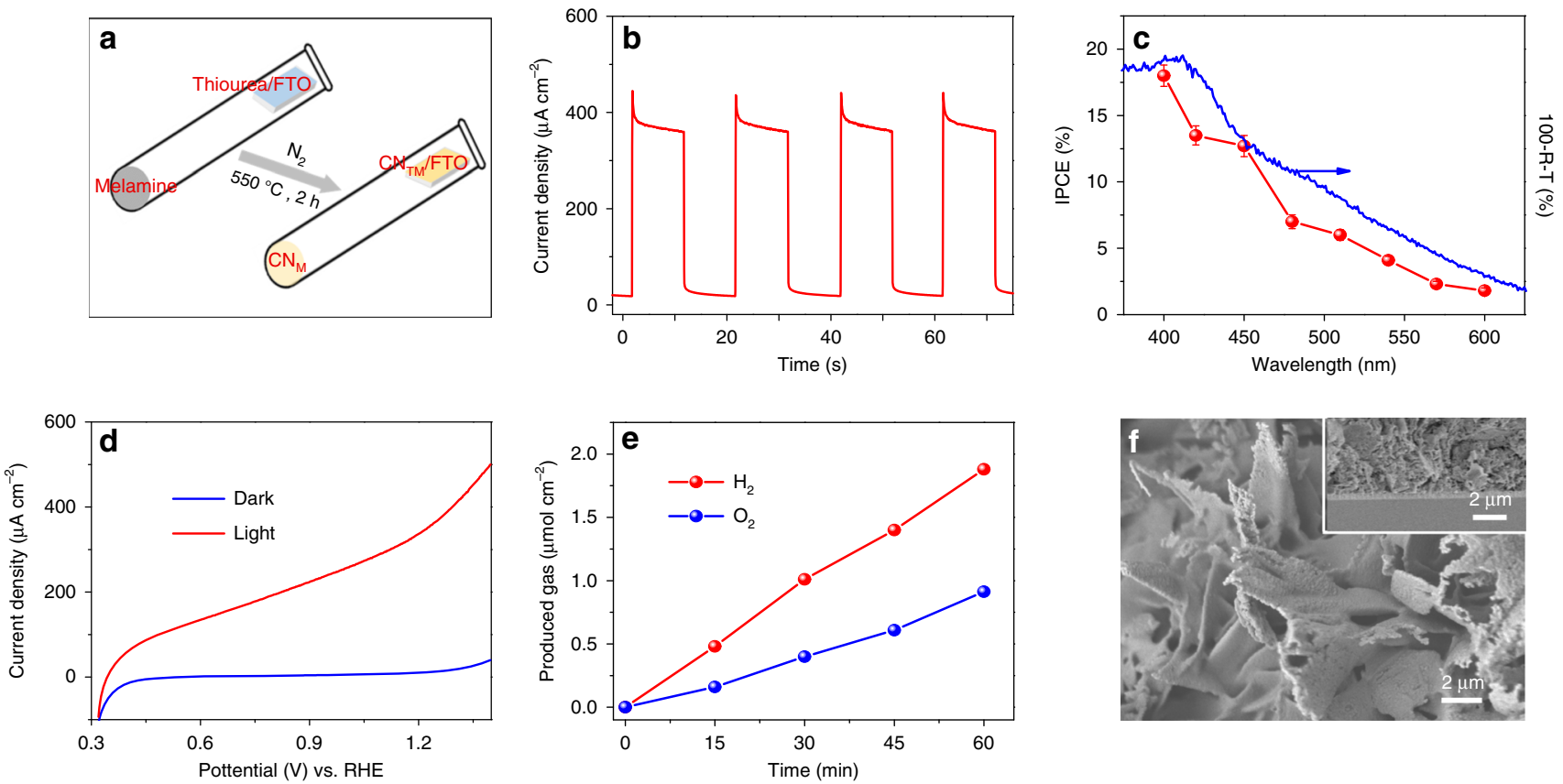

Fig. 5 Characterization of $\mathbf{C N}_{\mathbf{T M}}$ photoanodes. a Schematic synthetic process of $\mathrm{CN}_{\mathrm{TM}}$ film on FTO. b Photocurrent density (chronoamperometry) upon 1sun cycling illumination of $\mathrm{CN}_{\mathrm{TM}}$ electrode at $1.23 \mathrm{~V}$ vs. RHE in $0.1 \mathrm{M} \mathrm{KOH}$. $\mathbf{c I P C E}$ plots of $\mathrm{CN}_{\mathrm{TM}}$ as a function of incident wavelength in $0.1 \mathrm{M} \mathrm{KOH}$ and the corresponding UV-Vis spectrum of the $\mathrm{CN}_{T M}$ electrode. $\mathbf{d} \mathrm{LSV}$ curves of $\mathrm{CN}_{\mathrm{TM}}$ electrode in $0.1 \mathrm{M} \mathrm{KOH}$. e Time-production plot of the $\mathrm{H}_{2}$ and $\mathrm{O}_{2}$ generated from the PEC system with $\mathrm{CN}_{\mathrm{TM}}$ at $1.23 \mathrm{~V}$ vs. RHE in $0.1 \mathrm{M} \mathrm{KOH}$ upon 1-sun illumination. $\mathbf{f}$ Top-view (inset: cross-sectional) $\mathrm{SEM}_{\mathrm{images}}$ of $\mathrm{CN}_{\mathrm{TM}}$ film on FTO. (The light yellow powder labeled as $\mathrm{CN}_{\mathrm{M}}$ in frame a refers to carbon nitride obtained by calcination of melamine powder at $550{ }^{\circ} \mathrm{C}$ for $2 \mathrm{~h}$ at the bottom of the tube). Each IPCE (\%) data point represents an average of three different $\mathrm{CN}_{\mathrm{TM}}$ electrodes; error bars represent standard deviation.

reaction. This oxidation is further observed in the $\mathrm{O} 1 \mathrm{~s}$ spectrum (Supplementary Fig. 30d), where a signal from N-C-O species appears at $531.2 \mathrm{eV}^{47}$. Furthermore, we characterized the $\mathrm{CN}$ layer after $12 \mathrm{~h}$ stability measurement to confirm the structural changes. Therefore, the decrease in photocurrent should be attributed to the partial oxidation of the $\mathrm{CN}$ photoanode and the weakening of crystallinity during the reaction in $0.1 \mathrm{M} \mathrm{KOH}$.

Generally, water-spitting under neutral conditions is appealing. Thus, we have also measured the performance of $\mathrm{CN}_{\mathrm{TM}}$ photoanodes in $0.1 \mathrm{M} \mathrm{Na}_{2} \mathrm{SO}_{4}(\mathrm{pH}=7.02)$. Supplementary Fig. 31a shows that it also exhibited an outstanding PEC performance with a photocurrent of $305 \mu \mathrm{A} \mathrm{cm}^{-2}$ at $1.23 \mathrm{~V}$ vs. RHE under one-sun illumination. Meanwhile, the $\mathrm{CN}_{\mathrm{TM}}$ electrode is more stable under such conditions and higher rates of gas evolution $\left(\mathrm{H}_{2}\right.$ and $\left.\mathrm{O}_{2}\right)$ were obtained relative to alkaline conditions $(0.1 \mathrm{M} \mathrm{KOH})$. Supplementary Fig. $31 \mathrm{~b}$ shows there is almost no loss of photocurrent during the first $30 \mathrm{~min}$. After an hour, the remaining photocurrent is about $72 \%$ of the initial photocurrent. The detected $\mathrm{H}_{2}$ and $\mathrm{O}_{2}$ were 2.26 and $1.08 \mu \mathrm{mol} \mathrm{h}-1 \mathrm{~cm}^{-2}$ (Supplementary Fig. 31c-d), respectively, corresponding to $\mathrm{FE}$ of $55 \%$ for $\mathrm{H}_{2}$ and $52 \%$ for $\mathrm{O}_{2}$.

Despite the introduction of melamine, the chemical structure, composition, as well as the morphology of the synthesized $\mathrm{CN}_{\mathrm{TM}}$ film remains similar to $\mathrm{CN}_{\mathrm{T}}$ with slight surface modification of the nanosheets (Fig. $5 \mathrm{f}$ and Supplementary Figs. 32-34). In addition, a small redshift of the direct optical bandgap from 2.33 to $2.26 \mathrm{eV}$ is observed (Fig. 5c and Supplementary Fig. 35a). Combined with the results of Mott-Schottky measurements (Supplementary Fig. 35b, c), the conduction band and valence band positions of $\mathrm{CN}_{\mathrm{TM}}$ electrode are -1.21 and $1.05 \mathrm{eV}$ vs. $\mathrm{Ag} / \mathrm{AgCl}$, respectively (see scheme in Supplementary Fig. 35d), which thermodynamically allow both water reduction and oxidation. Moreover, electrochemical active surface area (ECSA) measurements (Supplementary Fig. 36) demonstrate that the ECSA of the $\mathrm{CN}_{\mathrm{TM}}$ electrode is higher than that of the $\mathrm{CN}_{\mathrm{T}}$ electrode, which is in line with the calculated Brunauer-Emmet-Teller (BET) specific surface area from $\mathrm{N}_{2}$ sorption experiments $\left(9.2 \mathrm{~m}^{2} \mathrm{~g}^{-1}\right.$ for $\mathrm{CN}_{\mathrm{TM}} \mathrm{vs}$. $6.1 \mathrm{~m}^{2} \mathrm{~g}^{-1}$ for $\mathrm{CN}_{\mathrm{T}}$, Supplementary Fig. 37). The ECSA and BET analysis suggest that the $\mathrm{CN}_{\mathrm{TM}}$ layer has more accessible sites for PEC reactions. In addition, electrochemical impedance spectroscopy (EIS) measurements (Supplementary Figs. 8 and 38) reveal that the introduction of melamine decreases the charge transfer resistance of holes from the $\mathrm{CN}$ layer to the solution.

Adhesion test. On the other hand, the addition of melamine during the synthesis increases the pressure inside the tube, which results in better contact between the $\mathrm{CN}$ and the FTO substrate (Fig. 5f, inset). We note that melamine can be replaced with another monomer (e.g., $\mathrm{NH}_{4} \mathrm{SCN}$, who's photoresponse is shown in Supplementary Fig. 39) that produces significant vapor pressure, leading to enhanced PEC performance. The latter accentuates the importance of the induced pressure during the film synthesis over the final performance. To confirm the strong adhesion, the prepared $\mathrm{CN}_{\mathrm{TM}}$ electrode was subjected to ultrasonication and adhesive tape testing. After $5 \mathrm{~min}$ of ultrasonication, only slight turbidity is detected in the liquid (Supplementary Fig. 40), which mainly resulted from $\mathrm{CN}$ powder at the surface of the photoactive $\mathrm{CN}$ film. Additional ultrasonication for a total of 30 min did not increase the turbidity and the $\mathrm{CN}$ film remained unchanged. The tape adhesion experiment was then carried out on the same $\mathrm{CN}_{\mathrm{TM}}$ electrode (after sonication, Supplementary Fig. 41). The $\mathrm{CN}_{\mathrm{TM}}$ film remained intact even after an adhesive tape was pasted onto the film under pressure for $2 \mathrm{~h}$. A control experiment with $\mathrm{CN}_{\mathrm{T}}$ electrode (Supplementary Fig. 42a) shows that the $\mathrm{CN}_{\mathrm{T}}$ solution is more turbid than the $\mathrm{CN}_{\mathrm{TM}}$ one after 5 min of ultrasonication. It was clearly observed that with increasing ultrasonication time, the edges of the $\mathrm{CN}_{\mathrm{T}}$ film are slowly falling off. This shows that the adhesion between $\mathrm{CN}_{\mathrm{TM}}$ 
film and FTO is stronger than that of the $\mathrm{CN}_{\mathrm{T}}$ film. The better contact between the FTO and $\mathrm{CN}_{\mathrm{TM}}$ layer leads to lower resistance, which in turn enables the higher photocurrent and better stability. However, we note that most of the $\mathrm{CN}_{\mathrm{T}}$ film remains intact after $30 \mathrm{~min}$ of ultrasonication and a subsequent tape-test (Supplementary Fig. 42b), indicating that it is still robust.

\section{Discussion}

The reported simple, scalable, and versatile method allows the deposition of uniform carbon nitride layers with enhanced optical absorption and charge separation under illumination on various substrates. This deposition method relies on the fast growth of $\mathrm{CN}$ monomers directly on a substrate, followed by calcination at high temperature. Furthermore, we demonstrate that the introduction of melamine vapor during the calcination step significantly enhances the PEC activity of the $\mathrm{CN}$ electrodes thanks to surface modification. Detailed PEC studies unveil excellent hole extraction efficiency, up to $62 \%$, together with good photoresponse over the visible range up to $600 \mathrm{~nm}$ (IPCE $>12 \%$ at $450 \mathrm{~nm}$ ). The best $\mathrm{CN}$ film, based on thiourea as the starting monomer, exhibits a high photocurrent density of $353 \mu \mathrm{A} \mathrm{cm}^{-2}$, with FE of $53 \pm 1 \%$ for $\mathrm{H}_{2}$ and $51 \pm 1.5 \%$ for $\mathrm{O}_{2}$, and an IPCE value of $18 \%$ at $400 \mathrm{~nm}$ at $1.23 \mathrm{~V}$ vs. RHE in alkaline $(0.1 \mathrm{M}$ $\mathrm{KOH})$ aqueous solution without sacrificial agents, providing a benchmark for $\mathrm{CN}$ photoanode materials.

\section{Methods}

Chemicals. All the chemical reagents were used without further purification. Thiourea (99\%) and guanidine carbonate (GC) (99\%) from Acros Organics. Urea (99\%), dicyandiamide (DCDA) (99\%), and melamine (99\%) from Sigma-Aldrich. $\mathrm{NH}_{4} \mathrm{SCN}$ (NS) (98\%) from Alfa Aesar. $\mathrm{KOH}(85 \%)$ and $\mathrm{Na}_{2} \mathrm{SO}_{4}(99 \%)$ from LobaChemie. Methanol $(\geq 99.8 \%)$, ethanol $(\geq 99 \%)$, and acetone $(\geq 99 \%)$ from Bio-Lab Ltd. Triethanolamine (>99\%) from Carl Roth. Fluorine-doped tin oxide (FTO)coated glass (12-14 $\Omega \mathrm{sq}^{-1}$ ) was purchased from Xop Glass company, Spain. Before using, the FTOs were thoroughly washed with an aqueous detergent (Alconox) solution, acetone, and ethanol in sequence and dried at $60^{\circ} \mathrm{C}$. Deionized water $\left(18.2 \mathrm{M} \Omega \mathrm{cm}\right.$ resistivity at $25^{\circ} \mathrm{C}$, purified using a Millipore Direct-Q3 system) was used as the solvent for all the reported experiments.

Characterization. A PANalytical's Empyrean diffractometer was employed to conduct X-ray diffraction (XRD) measurements. Fourier transformed infrared (FTIR) spectra were collected on a Thermo Scientific Nicolet iN 10Mx infrared microscope. UV-Vis spectra were recorded on a Cary 100 spectrophotometer equipped with a diffuse reflectance accessory (DRA). An Edinburgh FI/FSTCSPC 920 fluorimeter was used to collect photoluminescence (PL) spectra. The morphologies of the samples were characterized using a scanning electron microscope (SEM, JEOL JSM-7400F equipped with a FEG source) operated at $3.5 \mathrm{kV}$ using a secondary electrons detector. X-ray photoelectron spectroscopy (XPS) measurements were conducted on a Thermo Fisher Scientific ESCALAB 250 using monochromated $\mathrm{Ka} \mathrm{X}$-rays $(1486.6 \mathrm{eV})$, and all the binding energies obtained in XPS spectra were calibrated using the C $1 s$ peak at $284.6 \mathrm{eV} . \mathrm{N}_{2}$ $(99.999 \%)$ adsorption-desorption measurements were performed using a Quantachrome autosorb IQ2 at $77 \mathrm{~K}$. The specific surface area was calculated using the Brunauer-Emmet-Teller (BET) model. Pore-size distribution was calculated using non-localized density functional theory (NLDFT) from the nitrogen sorption measurements. The amount of generated gases in the cell of the PEC set up were analyzed using a gas chromatograph (Agilent $7820 \mathrm{GC}$ system) equipped with a thermal conductivity detector (TCD).

Material preparation. Thiourea/FTO: To deposit a thiourea film onto FTO, a clean FTO plate was immersed into a hot $\left(70^{\circ} \mathrm{C}\right)$ saturated thiourea aqueous solution and subsequently taken out. After the surface liquid was dried, a uniform film layer of thiourea on FTO was obtained. This step can be repeated several times to get different layers of thiourea film on FTO. Finally, the thiourea/FTO samples were dried in a $60^{\circ} \mathrm{C}$ oven for subsequent use. Thiourea films on other substrates were obtained similarly.

Urea/FTO, NS/FTO, and GC/FTO: The preparing procedure of urea/FTO, NS/ FTO, and GC/FTO is similar to that of thiourea/FTO, i.e., using urea, $\mathrm{NH}_{4} \mathrm{SCN}$, and guanidine carbonate instead of thiourea, respectively. Urea on other substrates was also prepared using the same method.

DCDA/FTO: First, a clean FTO was dipped into a saturated DCDA solution in methanol at room temperature and was dried under air to form DCDA seeds.
Secondly, the DCDA seeds/FTO was immersed into a hot $\left(70^{\circ} \mathrm{C}\right)$ saturated DCDA aqueous solution and subsequently taken out. A uniform layer of DCDA on FTO was thus obtained and dried at $60^{\circ} \mathrm{C}$. DCDA on other substrates was prepared using the same method.

$\mathrm{CN}_{\mathrm{T}} / \mathrm{FTO}$ : To obtain a carbon nitride film on FTO, thiourea/FTO substrates were encapsulated in a glass tube filled with nitrogen. The glass tube was inserted into a ceramic tube furnace with $\mathrm{N}_{2}$ atmosphere. The oven was heated at a rate of $5{ }^{\circ} \mathrm{C} \mathrm{min}-1$ to $500{ }^{\circ} \mathrm{C}$, when a calcination step at $500{ }^{\circ} \mathrm{C}$ for $2 \mathrm{~h}$ took place, resulting in a uniform yellow $\mathrm{CN}_{\mathrm{T}}$ layer on FTO.

$\mathrm{CN}_{\mathrm{U}} / \mathrm{FTO}, \mathrm{CN}_{\mathrm{D}} / \mathrm{FTO}, \mathrm{CN}_{\mathrm{NS}} / \mathrm{FTO}$, and $\mathrm{CN}_{\mathrm{GC}} / \mathrm{FTO}: \mathrm{CN}_{\mathrm{U}} / \mathrm{FTO}, \mathrm{CN}_{\mathrm{NS}} / \mathrm{FTO}$ and $\mathrm{CN}_{\mathrm{GC}} / \mathrm{FTO}$ were obtained by calcination of the corresponding precursor films at $500{ }^{\circ} \mathrm{C}$ for $2 \mathrm{~h}$ under $\mathrm{N}_{2}$. CN $/$ /FTO was obtained by calcination of DCDA/FTO at $500{ }^{\circ} \mathrm{C}$ for $4 \mathrm{~h}$ under $\mathrm{N}_{2}$.

Carbon nitride $\left(\mathrm{CN}_{\mathrm{T}}, \mathrm{CN}_{\mathrm{U}}\right.$, and $\left.\mathrm{CN}_{\mathrm{D}}\right)$ films on other substrates were similarly obtained by changing the substrate on which the precursor deposition occurred.

$\mathrm{CN}_{\mathrm{TM}} / \mathrm{FTO}$ : First, $1.0 \mathrm{~g}$ of melamine powder was added to the bottom of the tube, then the thiourea/FTO was placed close to the nozzle. The tube was then purged with $\mathrm{N}_{2}$, closed, and placed into an $\mathrm{N}_{2}$ oven. After calcination at $550{ }^{\circ} \mathrm{C}$ for $2 \mathrm{~h}$, the $\mathrm{CN}_{\mathrm{TM}} / \mathrm{FTO}$ was finally obtained. $\mathrm{CN}_{\mathrm{TNS}} / \mathrm{FTO}$ was similarly obtained by using $\mathrm{NH}_{4} \mathrm{SCN}$ powder instead of the melamine powder.

The dimensions of all the reported substrates (FTO, carbon paper, a glass slide) were $1.2 \mathrm{~cm} \times 2.5 \mathrm{~cm}$ unless otherwise specified.

Photoelectrochemical analysis. A Newport $300 \mathrm{~W}$ Xe arc lamp equipped with air mass AM 1.5G and water filters was used as a photoexcitation light source. The intensity of incident light simulated as one-sun illumination was calibrated using a Newport 919P thermopile detector. The electrochemical analysis measurements were conducted in a conventional three-electrode cell on an Autolab potentiostat (Metrohm, PGSTAT302N) system, using a $1 \mathrm{~cm}^{2} \mathrm{Pt}$ foil electrode as the counter electrode and an $\mathrm{Ag} / \mathrm{AgCl}$ electrode as the reference electrode, respectively. $0.1 \mathrm{M}$ $\mathrm{KOH}$ aqueous solution $(\mathrm{pH}=13)$ and $0.1 \mathrm{M} \mathrm{Na}_{2} \mathrm{SO}_{4}$ aqueous solution $(\mathrm{pH}=$ 7.02) were used as the electrolyte and were purged with argon to remove $\mathrm{O}_{2}$ before the electrochemical measurements. All the potentials were converted to reversible hydrogen electrode (RHE) values using the Nernst equation at room temperature:

$$
V_{\mathrm{RHE}}=V_{\mathrm{Ag} / \mathrm{AgCl}}+0.059 \times \mathrm{pH}+0.197 .
$$

Photocurrent measurements were conducted at $1.23 \mathrm{~V}$ vs. RHE and all photocurrents in the text and supporting materials were measured after three minutes of equilibration time unless otherwise specified. Mott-Schottky measurements were carried out in $1 \mathrm{M} \mathrm{Na}_{2} \mathrm{SO}_{4}$ aqueous solution using the same equipment.

Incident photon-to-current conversion efficiency (IPCE) values were calculated using:

$$
\operatorname{IPCE}(\%)=\frac{J\left(\mathrm{~A} \mathrm{~cm}^{-2}\right) \cdot 1240}{\lambda(\mathrm{nm}) \cdot I\left(\mathrm{~W} \mathrm{~cm}^{-2}\right)} \cdot 100 \%,
$$

where $J$ is the photocurrent density; $\lambda$ is the wavelength of the incident monochromic light, which is controlled by different optical bandpass filters (Newport 10BBPF10 series) of 400, 420, 450, 480,510, 540, 570, and $600 \mathrm{~nm}$; $I$ is the incident light power.

Hole extraction efficiency was calculated using:

$$
\eta(\%)=\frac{J_{\mathrm{KOH}}}{J_{\mathrm{TEOA}}} \cdot 100 \% .
$$

It is assumed that the extraction rate of photogenerated holes in the system is $100 \%$ after the addition of a hole scavenger $(10 \% \mathrm{v} / \mathrm{v}$ TEOA $) . J_{\mathrm{KOH}}$ is the photocurrent density obtained in $0.1 \mathrm{M} \mathrm{KOH}$ aqueous solution, while $J_{\text {TEOA }}$ is the photocurrent density obtained in $0.1 \mathrm{M} \mathrm{KOH}$ containing $10 \%$ (v/v) TEOA.

The faradaic efficiency (FE) was calculated using:

$$
\mathrm{FE}(\%)=\frac{m \cdot n \cdot F}{I \cdot t} \cdot 100 \%,
$$

where $m$ is the number of moles of gas produced; $n$ is the number of reaction electrons; $F$ is the Faraday constant; $I$ is the photocurrent; $t$ is the reaction time.

\section{Data availability}

The data supporting the findings of this study are available from the corresponding author upon reasonable request.

Received: 9 May 2020; Accepted: 27 August 2020; Published online: 17 September 2020

\section{References}

1. Wang, X. et al. A metal-free polymeric photocatalyst for hydrogen production from water under visible light. Nat. Mater. 8, 76 (2009). 
2. Xiong, W., Huang, F. \& Zhang, R. Q. Recent developments in carbon nitride based films for photoelectrochemical water splitting. Sustain. Energy Fuels 4 , 485-503 (2020).

3. Ong, W. J., Tan, L. L., Ng, Y. H., Yong, S. T. \& Chai, S. P. Graphitic carbon nitride $\left(\mathrm{g}-\mathrm{C}_{3} \mathrm{~N}_{4}\right)$-based photocatalysts for artificial photosynthesis and environmental remediation: are we a step closer to achieving sustainability? Chem. Rev. 116, 7159-7329 (2016).

4. Dong, G., Zhao, L., Wu, X., Zhu, M. \& Wang, F. Photocatalysis removing of NO based on modified carbon nitride: The effect of celestite mineral particles. Appl. Catal. B 245, 459-468 (2019).

5. Xiao, K. et al. Artificial light-driven ion pump for photoelectric energy conversion. Nat. Commun. 10, 74 (2019).

6. Zhang, G. et al. Ionothermal synthesis of Triazine-Heptazine-based copolymers with apparent quantum yields of $60 \%$ at $420 \mathrm{~nm}$ for solar hydrogen production from "Sea Water". Angew. Chem. Int. Ed. 57, 9372-9376 (2018).

7. Volokh, M., Peng, G., Barrio, J. \& Shalom, M. Carbon nitride materials for water splitting photoelectrochemical cells. Angew. Chem. Int. Ed. 58, 6138-6151 (2019).

8. Zhao, T. et al. Ultrafast condensation of carbon nitride on electrodes with exceptional boosted photocurrent and electrochemiluminescence. Angew. Chem. Int. Ed. 59, 1139-1143 (2020).

9. $\mathrm{Li}, \mathrm{X}$. et al. Recent advances in $3 \mathrm{D} \mathrm{g}-\mathrm{C}_{3} \mathrm{~N}_{4}$ composite photocatalysts for photocatalytic water splitting, degradation of pollutants and $\mathrm{CO}_{2}$ reduction. J. Alloy. Compd 802, 196-209 (2019).

10. Huang, M., Bian, J., Xiong, W., Huang, C. \& Zhang, R. Low-dimensional Mo: $\mathrm{BiVO}_{4}$ photoanodes for enhanced photoelectrochemical activity. J. Mater. Chem. A 6, 3602-3609 (2018).

11. Kim, T. W. \& Choi, K. S. Nanoporous $\mathrm{BiVO}_{4}$ photoanodes with dual-layer oxygen evolution catalysts for solar water splitting. Science 343, 990-994 (2014).

12. Huang, C., Bian, J. \& Zhang, R. Q. Role of $\mathrm{Cl}$ ion desorption in photocurrent enhancement of the annealed rutile single-crystalline $\mathrm{TiO}_{2}$ nanorod arrays. J. Phys. Chem. C 121, 18892-18899 (2017).

13. Chang, K. et al. Targeted synthesis of $2 \mathrm{H}$-and $1 \mathrm{~T}$-phase $\mathrm{MoS}_{2}$ monolayers for catalytic hydrogen evolution. Adv. Mater. 28, 10033-10041 (2016).

14. May, M. M., Lewerenz, H. J., Lackner, D., Dimroth, F. \& Hannappel, T. Efficient direct solar-to-hydrogen conversion by in situ interface transformation of a tandem structure. Nat. Commun. 6, 8286 (2015).

15. Fang, Y., Li, X. \& Wang, X. Synthesis of polymeric carbon nitride films with adhesive interfaces for solar water splitting devices. ACS Catal. 8, 8774-8780 (2018).

16. Ruan, Q. et al. A nanojunction polymer photoelectrode for efficient charge transport and separation. Angew. Chem. Int. Ed. 56, 8221-8225 (2017).

17. Peng, G., Albero, J., Garcia, H. \& Shalom, M. A water-splitting carbon nitride photoelectrochemical cell with efficient charge separation and remarkably low onset potential. Angew. Chem. Int. Ed. 130, 16033-16037 (2018).

18. Fang, Y., Xu, Y., Li, X., Ma, Y. \& Wang, X. Coating polymeric carbon nitride photoanodes on conductive $\mathrm{Y}: \mathrm{ZnO}$ nanorod arrays for overall water splitting. Angew. Chem. Int. Ed. 57, 9749-9753 (2018).

19. Peng, G., Xing, L., Barrio, J., Volokh, M. \& Shalom, M. A general synthesis of porous carbon nitride films with tunable surface area and photophysical properties. Angew. Chem. Int. Ed. 57, 1186-1192 (2018).

20. Lou, S. et al. Comparison study of the photoelectrochemical activity of carbon nitride with different photoelectrode configurations. ACS Appl. Mater. Interfaces 8, 22287-22294 (2016).

21. Bian, J. et al. Thermal vapor condensation of uniform graphitic carbon nitride films with remarkable photocurrent density for photoelectrochemical applications. Nano Energy 15, 353-361 (2015).

22. Bian, J. et al. Efficiency enhancement of carbon nitride photoelectrochemical cells via tailored monomers design. Adv. Energy Mater. 6, 1600263 (2016).

23. Huang, M. et al. Collaborative enhancement of photon harvesting and charge carrier dynamics in carbon nitride photoelectrode. Appl. Catal. B 237, 783-790 (2018).

24. Fan, X. et al. Layered double hydroxides decorated graphic carbon nitride film as efficient photoanodes for photoelectrochemical water splitting. Catal. Today 335, 423-428 (2019).

25. Xie, X., Fan, X., Huang, X., Wang, T. \& He, J. In situ growth of graphitic carbon nitride films on transparent conducting substrates via a solvothermal route for photoelectrochemical performance. RSC $A d v$. 6, 9916-9922 (2016).

26. Liu, J. et al. Microcontact-printing-assisted access of graphitic carbon nitride films with favorable textures toward photoelectrochemical application. Adv. Mater. 27, 712-718 (2015).

27. $\mathrm{Xu}$, J. et al. Liquid-based growth of polymeric carbon nitride layers and their use in a mesostructured polymer solar cell with Voc exceeding 1 V. J. Am. Chem. Soc. 136, 13486-13489 (2014).
28. Zhang, W. et al. One-pot synthesis of nickel-modified carbon nitride layers toward efficient photoelectrochemical cells. ACS Appl. Mater. Interfaces $\mathbf{9}$, 32667-32677 (2017)

29. Zhang, J., Zhang, M., Lin, L. \& Wang, X. Sol processing of conjugated carbon nitride powders for thin-film fabrication. Angew. Chem. Int. Ed. $\mathbf{5 4}$ 6297-6301 (2015).

30. Guo, B. et al. Vertically aligned porous organic semiconductor nanorod array photoanodes for efficient charge utilization. Nano Lett. 18, 5954-5960 (2018).

31. Peng, G., Qin, J., Volokh, M., Liu, C. \& Shalom, M. Graphene oxide in carbon nitride: from easily processed precursors to a composite material with enhanced photoelectrochemical activity and long-term stability. J. Mater. Chem. A 7, 11718-11723 (2019).

32. Safaei, J. et al. Graphitic carbon nitride $\left(\mathrm{g}-\mathrm{C}_{3} \mathrm{~N}_{4}\right)$ electrodes for energy conversion and storage: a review on photoelectrochemical water splitting, solar cells and supercapacitors. J. Mater. Chem. A 6, 22346-22380 (2018).

33. Qin, J., Wang, S., Ren, H., Hou, Y. \& Wang, X. Photocatalytic reduction of $\mathrm{CO}_{2}$ by graphitic carbon nitride polymers derived from urea and barbituric acid. Appl. Catal. B 179, 1-8 (2015).

34. Xiang, Q., Yu, J. \& Jaroniec, M. Preparation and enhanced visible-light photocatalytic $\mathrm{H}_{2}$ production activity of graphene/ $\mathrm{C}_{3} \mathrm{~N}_{4}$ composites. J. Phys. Chem. C 115, 7355-7363 (2011)

35. Ye, C. et al. Enhanced driving force and charge separation efficiency of protonated $\mathrm{g}-\mathrm{C}_{3} \mathrm{~N}_{4}$ for photocatalytic $\mathrm{O}_{2}$ evolution. ACS Catal. 5, 6973-6979 (2015).

36. Zhang, G. et al. Optimizing optical absorption, exciton dissociation, and charge transfer of a polymeric carbon nitride with ultrahigh solar hydrogen production activity. Angew. Chem. Int. Ed. 56, 13445-13449 (2017).

37. Abisdris, L. et al. Electrophoretic deposition of supramolecular complexes for the formation of carbon nitride films. Sustain. Energy Fuels 4, 3879-3883 (2020).

38. Zhang, G., Zhang, J., Zhang, M. \& Wang, X. Polycondensation of thiourea into carbon nitride semiconductors as visible light photocatalysts. J. Mater. Chem. 22, 8083-8091 (2012).

39. Ong, W. J., Tan, L. L., Chai, S. P., Yong, S. T. \& Mohamed, A. R. Surface charge modification via protonation of graphitic carbon nitride $\left(\mathrm{g}-\mathrm{C}_{3} \mathrm{~N}_{4}\right)$ for electrostatic self-assembly construction of $2 \mathrm{D} / 2 \mathrm{D}$ reduced graphene oxide $(\mathrm{rGO}) / \mathrm{g}-\mathrm{C}_{3} \mathrm{~N}_{4}$ nanostructures toward enhanced photocatalytic reduction of carbon dioxide to methane. Nano Energy 13, 757-770 (2015).

40. Barrio, J. et al. Unprecedented centimeter-long carbon nitride needles: synthesis, characterization and applications. Small 14, 1800633 (2018).

41. Chang, F. et al. Enhanced visible-light-driven photocatalytic performance of porous graphitic carbon nitride. Appl. Surf. Sci. 358, 270-277 (2015).

42. Peng, G., Volokh, M., Tzadikov, J., Sun, J. \& Shalom, M. Carbon nitride/ reduced graphene oxide film with enhanced electron diffusion length: an efficient photo-electrochemical cell for hydrogen generation. Adv. Energy Mater. 8, 1800566 (2018).

43. Chang, S. M. \& Liu, W. S. Surface doping is more beneficial than bulk doping to the photocatalytic activity of vanadium-doped $\mathrm{TiO}_{2}$. Appl. Catal. B 101, 333-342 (2011).

44. Matis, B. R. et al. Surface doping and band gap tunability in hydrogenated graphene. ACS nano 6, 17-22 (2012).

45. Liu, X. et al. Ozone treatment of graphitic carbon nitride with enhanced photocatalytic activity under visible light irradiation. J. Colloid Interface Sci. 505, 919-928 (2017).

46. Ming, L., Yue, H., Xu, L. \& Chen, F. Hydrothermal synthesis of oxidized g$\mathrm{C}_{3} \mathrm{~N}_{4}$ and its regulation of photocatalytic activity. J. Mater. Chem. A 2 , 19145-19149 (2014)

47. Li, J. et al. A facile approach to synthesize novel oxygen-doped g- $\mathrm{C}_{3} \mathrm{~N}_{4}$ with superior visible-light photoreactivity. Chem. Commun. 48, 12017-12019 (2012).

\section{Acknowledgements}

This work is financially supported by the Israel Science Foundation, Grant No. 1161/17 and ISF-NSFC Grant No. 2969/19. This project has received funding from the European Research Council (ERC) under the European Union's Horizon 2020 Research and Innovation Programme (Grant Agreement No. 849068). J.Q. thanks to the National Natural Science Foundation of China (No. 21902095).

\section{Author contributions}

J.Q. performed most of the experiments, analyzed the data, and wrote the initial draft of the manuscript. J.B., G.P., J.T., L.A., and M.V. performed some material characterization. M.V. took part in analysis and writing. M.S. supervised the study and co-wrote the paper. All the authors discussed the results and reviewed the manuscript.

\section{Competing interests}

The authors declare no competing interests. 


\section{Additional information}

Supplementary information is available for this paper at https://doi.org/10.1038/s41467020-18535-0.

Correspondence and requests for materials should be addressed to M.S.

Peer review information Nature Communications thanks Robert Godin and other, anonymous, reviewers for their contributions to the peer review of this work.

Reprints and permission information is available at http://www.nature.com/reprints

Publisher's note Springer Nature remains neutral with regard to jurisdictional claims in published maps and institutional affiliations. (c) (i) Open Access This article is licensed under a Creative Commons Attribution 4.0 International License, which permits use, sharing, adaptation, distribution and reproduction in any medium or format, as long as you give appropriate credit to the original author(s) and the source, provide a link to the Creative Commons license, and indicate if changes were made. The images or other third party material in this article are included in the article's Creative Commons license, unless indicated otherwise in a credit line to the material. If material is not included in the article's Creative Commons license and your intended use is not permitted by statutory regulation or exceeds the permitted use, you will need to obtain permission directly from the copyright holder. To view a copy of this license, visit http://creativecommons.org/licenses/by/4.0/.

(C) The Author(s) 2020 